\title{
Tailoring cutinase activity towards polyethylene terephthalate and polyamide 6,6 fibers
}

\author{
Rita Araújo $^{\text {a,b,1 }}$, Carla Silva ${ }^{\text {a, }}$, Alexandre O’Neill ${ }^{\mathrm{a}, 1}$, Nuno Micaelo $^{\mathrm{c}}$, \\ Georg Guebitz ${ }^{\mathrm{d}}$, Cláudio M. Soares ${ }^{\mathrm{c}}$, Margarida Casal ${ }^{\mathrm{b}}$, Artur Cavaco-Paulo ${ }^{\mathrm{a}, *}$ \\ ${ }^{a}$ University of Minho, Textile Engineering Department, 4800-058 Guimarães, Portugal \\ ${ }^{\mathrm{b}}$ University of Minho, Biology Department, 4710-057 Braga, Portugal \\ ${ }^{\mathrm{c}}$ University Nova de Lisboa, Institute of Chemical and Biological Technology, 2781-901 Oeiras, Portugal \\ ${ }^{\mathrm{d}}$ Technical University of Graz, Department of Environmental Biotechnology, 8010 Graz, Austria
}

Received 18 July 2006; received in revised form 12 December 2006; accepted 21 December 2006

\begin{abstract}
Cutinase from Fusarium solani pisi was genetically modified near the active site, by site-directed mutagenesis, to enhance its activity towards polyethylene terephthalate (PET) and polyamide 6,6 (PA 6,6) fibers. The mutations L81A, N84A, L182A, V184A and L189A were done to enlarge the active site in order to better fit a larger polymer chain. Modeling studies have shown enhanced free energy stabilization of model substrate tetrahedral intermediate (TI) bound at the enzyme active site for all mutants, for both model polymers. L81A and L182A showed an activity increase of four- and five-fold, respectively, when compared with the wild type, for PET fibers. L182A showed the one- and two-fold higher ability to biodegrade aliphatic polyamide substrates. Further studies in aliphatic polyesters seem to indicate that cutinase has higher ability to recognize aliphatic substrates.
\end{abstract}

(C) 2007 Elsevier B.V. All rights reserved.

Keywords: Cutinase; Biocatalysis; Polyester; Polyamide 6,6; Site-directed mutagenesis

\section{Introduction}

Cutinase from the fungus Fusarium solani pisi is a secreted enzyme that degrades cutin, the structural polyester of plants cuticle, being a versatile

\footnotetext{
* Corresponding author. Tel.: +351 253 510271; fax: +351253510293 .

E-mail address: artur@det.uminho.pt (A. Cavaco-Paulo).

1 These authors equally contributed to this work.
}

serine hydrolase showing unusual stereolytic activity (Carvalho et al., 1998). In vitro, cutinases display hydrolytic activity towards a broad variety of esters including triglycerides (Carvalho et al., 1998). Synthetic activities of cutinases have also been described for the production of triglycerides, polymers and agrochemicals containing one or more chiral centers (Carvalho et al., 1999). Our group showed for the first time the ability of cutinase to biodegrade polyamide 6,6 (PA 6,6) and vinyl acetate (co-monomer of acrylic 
fiber) fibers (Silva et al., 2005) and we also confirmed that cutinase is an enzyme with a high potential to hydrolyze and improve the surface properties of polyethylene terephthalate (PET) fibers in an environmentally friendly way (Silva et al., 2005). However, these synthetic fibers are non-natural substrates and, despite the broad specific activity of cutinase, turnover rates are very low. The analysis of the 3D structure of the cutinase from Fusarium solani pisi (PDB code 1CEX) (Longhi et al., 1997) shows that the external, but closed active site is hindering the access to the fiber substrate. In the present work, site-directed mutagenesis was performed on selected residues allowing the fit of a larger substrate in the active site.

A comparative discussion is made on the biodegradation ability of the several mutations based on modeling data, enzyme activity and protein adsorption levels from the polymeric substrates. The cutinase ability to biodegrade polyamide aliphatic substrates was confirmed by measuring the activity on hydrophobic aliphatic polyesters, which present a similar structure to cutin. Amidase and esterase activity of cutinase is also discussed.

\section{Materials and methods}

\subsection{Fibers and reagents}

Oligonucleotides $(0.05 \mu \mathrm{mol}$ scale $)$ were purchased from MWG Biotech, Germany. Restriction and modification enzymes were supplied by Roche Applied Science, Germany. Accuzyme DNA Polymerase was obtained from Bioline, Germany. The Escherichia coli strain BL21(DE3) and the plasmid vector pET25b (+) were purchased from Novagen, Madison, WI, USA. The succinic acid kit Cat No. 10176281035 was obtained from R-Biopharm, Germany.

For biodegrading experiments it was used commercial polyamide woven fabric, a plain woven structure with $63 \mathrm{~g} / \mathrm{m}^{2}$ and commercial polyester taffeta fabric with $62 \mathrm{~g} / \mathrm{m}^{2}$, both supplied by Rhodia, Switzerland. All other reagents used were laboratory grade reagents.

\subsection{Modeling studies}

Modeling studies were performed using the cutinase X-ray structure of Longhi et al. (1997), PDB code
1CEX, solvated dodecahedral water box (minimum distance between the protein and box wall of $0.8 \mathrm{~nm}$ ), with the model substrates tetrahedral intermediate (TI) bound at the enzyme active site. These model substrates, 1,2-ethanodiol dibenzoate and PA 6,6 mimics the polyester and polyamide hydrophobic properties, respectively, and are suitable models for simulation and experimental studies. The formation of the TI is known to be the rate limiting step in the catalytic mechanism of serine proteases (Warshel et al., 1989). This model system was chosen in order to evaluate the free energy of stabilization of the TI provided by selected mutations to alanine of residues located at the enzyme active site (Fig. 1): L182A, V184A, L189A, L81A and N84A according to Scheme 1. These mutations were initially designed as possible changes leading to a better fitting of the 1,2-ethanodiol dibenzoate and PA 6,6 TI in the active site. Molecular dynamics/molecular mechanics (MD/MM) simulations (van Gunsteren and Berendsen, 1990) were performed with the GROMACS package (Berendsen et al., 1995; Lindahl et al., 2001) Version 3.1.4, using the GROMOS96 force field (Scott et al., 1999) with an integration time step of $2 \mathrm{fs}$. Five simulations (with different initial velocities) were made, both with the free enzyme and enzyme bound to the TI. Bond lengths of the solute were constrained with LINCS and the ones of water with SETTLE. Non-bonded interactions were calculated using a twin-range method with short and long range cut-offs of 8 and $14 \AA$, respectively. The SPC water model was used (Hermans et al., 1984). A reaction field correction (Tironi et al., 1995; Barker and

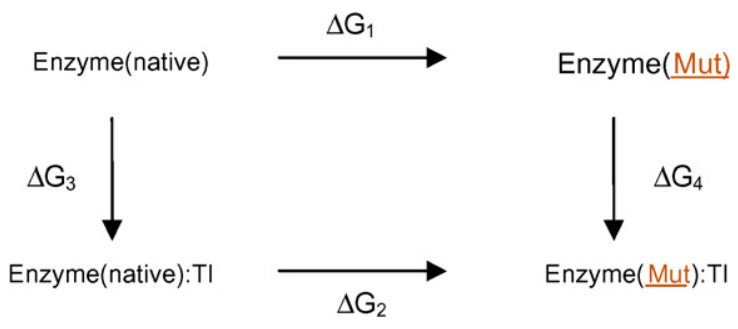

Scheme 1. Thermodynamic cycle employed in the calculation of the relative free energy of stabilization of the model substrate TI between native and mutant enzymes, $\Delta \Delta G_{\text {native-Mut }}=\Delta G_{2}-\Delta G_{1}$. This thermodynamic cycle evaluates the preferential stability of the model substrate TI to be bound to the native or to the mutated enzyme. This is achieved through the calculation of $\Delta G_{1}$ and $\Delta G_{2}$ by thermodynamic integration (Beveridge and Dicapua, 1989). 
(A)

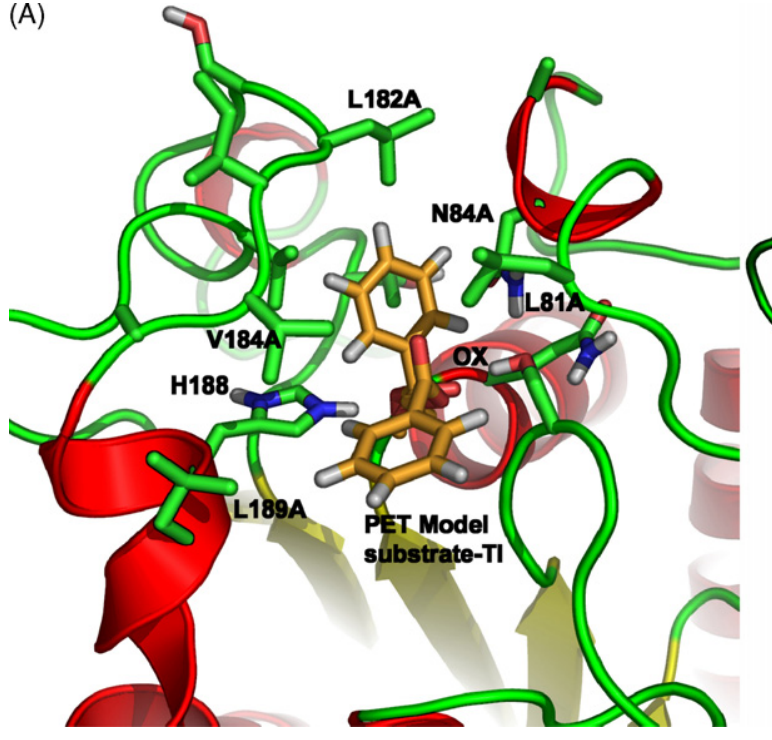

(B)

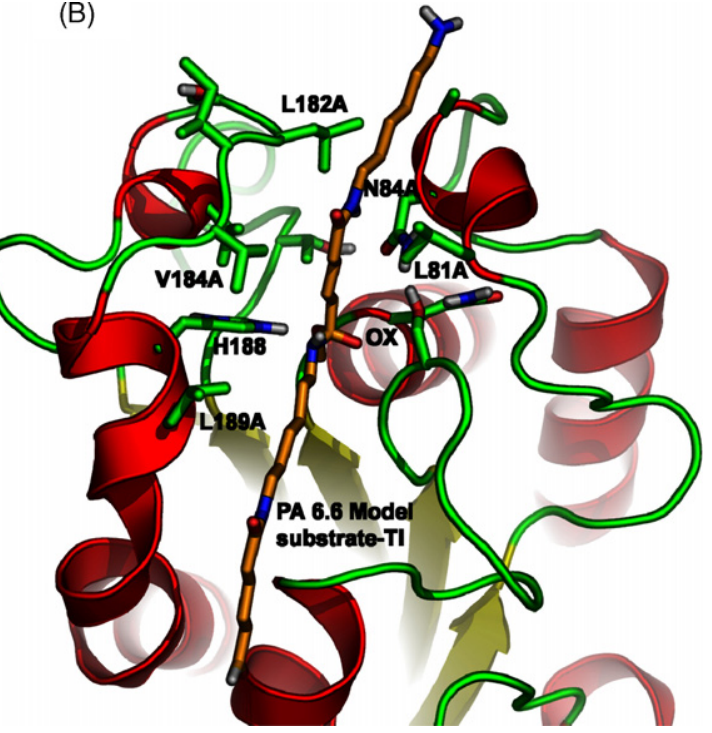

Fig. 1. Detail of the active site X-ray structure of cutinase with the energy minimized structure of the TI of 1,2-ethanodiol dibenzoate (PET model substrate) (A) and PA 6,6 (B). The catalytic histidine (H188) and oxianion-hole (OX) are shown. Residues mutated in this study are labeled as: L81A, N84A, L182A, V184A and L189A.

Watts, 1973) for electrostatic interactions was applied, considering a dielectric of 54 for SPC water (Smith and van Gunsteren, 1994). The solute and solvent were coupled to two separate heat baths (Berendsen et al., 1984) with temperature coupling constants of $0.1 \mathrm{ps}$ and reference temperatures of $300 \mathrm{~K}$. The pressure control was implemented with a reference pressure of $1 \mathrm{~atm}$ and a relaxation time of $0.5 \mathrm{ps}$ (Berendsen et al., 1984). Free energy calculations (Beveridge and Dicapua, 1989) were made using thermodynamic integration by slowly changing the selected residues to alanine using 11 equally spaced sampling points $100 \mathrm{ps}$ each. Five replicates based on the five different trajectories were made for each mutation. The trajectories were run for $2 \mathrm{~ns}$ prior to the free energy calculations.

\subsection{Plasmid construction and protein expression}

The native cutinase gene sequence was PCR-amplified with the primers CutFor (5'-CGGGATCCCATGAAACAAAGCACTATTGCACTG- ${ }^{\prime}$ ) and CutRev (5'-CGAGCTCGCAGCAGAACCACGGACAGCC-

$3^{\prime}$ ) from the vector pDrFST (kindly provided by Professor G. Georgiou, Institute for Cell and Molecular Biology, University of Texas, Austin, USA) (Griswold et al., 2003). The PCR product was restricted with
BamHI and SacI and cloned into the BamHI and $\mathrm{SacI}$ restricted and dephosphorilated pET25b(+), resulting in the final pCWT vector. The plasmid construct was verified by DNA sequencing. The sequencing was performed following the method of Sanger et al. (1977), using an ABI PRISM 310 Genetic Analyzer.

Site-directed mutagenesis was performed using recombinant PCR technique (Ansaldi et al., 1996). This approach is based on the PCR amplification of an entire plasmid by mutagenic primers (Table 1) divergently oriented but overlapping at their $5^{\prime}$ ends. The mutagenic nucleotides are located only in the reverse primer.

The pET25b (+) carrying native and genetically modified cutinases were first established in E. coli strain XL1 Blue, according to the SEM method (Inoue et al., 1990), and the presence of each specific mutation was confirmed by sequencing. DNA cloning and manipulation were performed according to the standard protocols (Sambroock et al., 1989). T7 expression host strain BL21(DE3) was used for protein expression. Strains were grown at $37^{\circ} \mathrm{C}$ in Luria-Broth medium, supplemented with $50 \mu \mathrm{g} / \mathrm{ml}$ ampicillin until an absorbance $A_{600 \mathrm{~nm}}$ of 0.6 was reached. Cells were then induced by adding isopropyl-1-thio- $\beta$-Dgalactopyranoside (IPTG) (final concentration $1 \mathrm{mM}$ ), followed by $16 \mathrm{~h}$ at $18^{\circ} \mathrm{C}$. The cells were harvested 
Table 1

Primers used for site-directed mutagenesis of cutinase gene from Fusarium Solani pisi

\begin{tabular}{|c|c|c|c|}
\hline Mutation & Primer $\left(5^{\prime} \rightarrow 3^{\prime}\right)$ & $\mathrm{bp}$ & $\mathrm{GC} \%$ \\
\hline \multirow[t]{2}{*}{ L81A } & F1 СТСТСССТCGCGGAACCTCTAGCGCCGCAATCAGGGAGA & 39 & 64.1 \\
\hline & R1 CTAGAGGTTCCGCGAGGGAGAGCATTGTCTCCGGCAGTGGCTCGGTAGGCAC & 52 & 63.5 \\
\hline \multirow[t]{2}{*}{ N84A } & F2 GCGGAACCTCTAGCGCCGCAATCAGGGAGATGCTCGGTC & 39 & 64.1 \\
\hline & R2 ATTGCGGCGCTAGAGGTTCCGCGAGGGAGAGCGGCGTCTCCAAGAGTGGCTC & 52 & 65.4 \\
\hline \multirow[t]{2}{*}{ L182A } & F3 CACCTCACTTGGCTTATGGTCCTGATGCTCGTGGCCCTG & 39 & 59.0 \\
\hline & R3 GGACCATAAGCCAAGTGAGGTGCAGCAACGATGGCGCTACCAGTACAAACGA & 52 & 53.8 \\
\hline \multirow[t]{2}{*}{ V184A } & F4 ACTTGGCTTATGGTCCTGATGCTCGTGGCCCTGCCCCTG & 39 & 61.5 \\
\hline & R4 GCATCAGGACCATAAGCCAAGTGAGGTGCAGCGGCGATCAAGCTACCAGTAC & 52 & 55.8 \\
\hline \multirow[t]{2}{*}{ L189A } & F5 CTGATGCTCGTGGCCCTGCCCCTGAGTTCCTCATCGAGA & 39 & 61.5 \\
\hline & 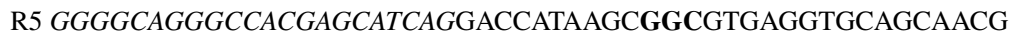 & 51 & 66.7 \\
\hline
\end{tabular}

The codons corresponding to the specific mutations introduced are indicated in bold. The overlapping regions (22 bp) of primers forward (F) and reverse $(\mathrm{R})$ are italic.

by centrifugation ( $5000 \mathrm{rpm}$ for $10 \mathrm{~min}$ ) and washed twice with phosphate buffered saline solution $(10 \mathrm{mM}$ $\mathrm{Na}_{2} \mathrm{HPO}_{4}, 2 \mathrm{mM} \mathrm{KH}{ }_{2} \mathrm{PO}_{4}, 137 \mathrm{mM} \mathrm{NaCl}, 3 \mathrm{mM} \mathrm{KCl}$, $\mathrm{pH}$ 7.4), supplemented with a mixture of protease inhibitors. Ultrasonic treatment of bacterial cells was performed at $20 \mathrm{KHz}$ with a $13-\mathrm{mm}$ probe in an Ultrasonic Processor GEX 400. Four 2-min pulses with $2 \mathrm{~min}$ in ice between each pulse were performed. The lysate was centrifuged for $30 \mathrm{~min}$ at $14000 \mathrm{rpm}$ at $4{ }^{\circ} \mathrm{C}$. The supernatant, periplasmatic fraction was decanted and reserved for cutinase purification.

\subsection{Protein purification by immobilized metal affinity chromatography (IMAC)}

An IMAC system was performed with the XK 16 column (Amersham Pharmacia Biotech) containing $2.5 \mathrm{ml}$ Chelating Sepharose Fast Flow (Amersham Pharmacia Biotech). The XK 16 column was linked to an AKTA P900 workstation (Amersham Pharmacia Biotech). After loading with $3 \mathrm{ml} 0.1 \mathrm{M} \mathrm{NiSO}_{4}$ in $\mathrm{H}_{2} \mathrm{O}$, equilibration was performed with $10 \mathrm{mM}$ imidazole, $0.5 \mathrm{M} \mathrm{NaCl}$ and $20 \mathrm{mM}$ phosphate buffer $\mathrm{pH}$ 7.6. Samples were applied onto the column at a flow rate of $2 \mathrm{ml} / \mathrm{min}$, followed by washing with the equilibration buffer until the UV baseline was reached. Elution was performed with a buffer containing $500 \mathrm{mM}$ imidazole, $0.5 \mathrm{M} \mathrm{NaCl}$ and $20 \mathrm{mM}$ phosphate buffer, $\mathrm{pH}$ 7.6. The activity-containing fractions were collected and used as the pure enzyme for polyester enzymatic hydrolysis.

Sodium dodecyl sulphate-polyacrylamide gel electrophoresis, using a Tris-SDS-glycine buffer system, was used to monitor the fractions obtained from IMAC (Laemmli, 1970). Protein detection was done by Coomassie Brilliant Blue R250, as well as by InVision His-tag In-gel Stain (Invitrogen, California, USA). The total protein concentration was estimated by the Bradford quantitative protein determination assay (Bradford, 1976) using bovine serum albumine as standard.

\subsection{Cutinase activity towards p-nitrophenyl butyrate ( $p-N P B)$}

The stereolityc activity of cutinase was determined spectrophotometrically following the hydrolysis of $p$ nitrophenyl butyrate ( $p$-NPB) at $400 \mathrm{~nm}$ (Shirai and Jackson, 1982). One unit of activity was defined as the amount of enzyme required to convert $1 \mu \mathrm{mol}$ of $p$-nitrophenyl butyrate to $p$-nitrophenol ( $p$-NP) per minute. All the activity assays were done in triplicate.

\subsection{Cutinase activity towards polyethylene terephthalate (PET) and polyamide 6,6 (PA 6,6) fibers}

One gram of polyamide fabric was incubated with $20 \mathrm{mg} / \mathrm{l}$ of native and genetically modified mutant enzymes, in $300 \mathrm{ml}$ of phosphate buffer $(0.1 \mathrm{M} \mathrm{NaOH}$, $0.1 \mathrm{M} \mathrm{KH}_{2} \mathrm{PO}_{4}, \mathrm{pH} 7.5$ ) at $37^{\circ} \mathrm{C}$. For this experiment, the samples were incubated in Erlenmeyers using a shaking bath with orbital agitation $(90 \mathrm{rpm})$ for $48 \mathrm{~h}$. After treatment all samples were washed with $2 \mathrm{~g} / \mathrm{l}$ of $\mathrm{Na}_{2} \mathrm{CO}_{3}$ for $2 \mathrm{~h}$, in order to stop the enzymatic reaction, 
followed by washing with $10 \mathrm{~g} / \mathrm{l}$ of Lutensol at $25^{\circ} \mathrm{C}$ for $1 \mathrm{~h}$. The same procedure was followed for PET fabrics with an incubation period of $24 \mathrm{~h}$. The hydrolysis products were quantified as previously described (O'Neill and Cavaco-Paulo, 2004; Silva and CavacoPaulo, 2004).

\subsection{Determination of protein adsorption}

The protein adsorption was obtained measuring the protein content in the incubation solutions before and after the enzymatic treatment of PET and PA 6,6 fabrics. The difference between the values obtained for these two periods measures the protein adsorbed by the substrates.

\subsection{Cutinase activity towards aliphatic polyesters}

In order to measure the activity of native and L182A cutinase mutant towards aliphatic substrates, $0.05 \mathrm{~g}$ of each substrates, poly(ethylene succinate), poly(1,3propylene succinate) and poly(1,4-butylene succinate) were incubated with $1 \mathrm{U}(\mu \mathrm{mol}$ of $p$-NP per $\mathrm{min}) / \mathrm{ml}$ in a $3 \mathrm{ml}$ phosphate buffer bath $(\mathrm{pH} 7.5)$ at $37^{\circ} \mathrm{C}$ for $5 \mathrm{~h}$. The activity towards aliphatic substrates was quantified by measuring succinic acid formation, using the succinic acid UV kit method.

The total protein concentration was estimated by the Bradford quantitative protein determination assay (Bradford, 1976) using bovine serum albumine as standard.
Table 2

Stabilization free energy of the model substrate TI estimated for the mutated enzymes

\begin{tabular}{|c|c|c|}
\hline \multirow[t]{2}{*}{ Mutation } & \multicolumn{2}{|c|}{$\Delta \Delta G(\mathrm{~kJ} / \mathrm{mol})$} \\
\hline & PA 6,6 & PET \\
\hline L182A & -3.80 & -4.81 \\
\hline L189A & -2.38 & -2.83 \\
\hline V184A & -2.44 & -1.81 \\
\hline L81A & -1.77 & -2.35 \\
\hline N84A & 15.95 & 14.64 \\
\hline
\end{tabular}

Free energies are calculated relatively to the native enzyme.

\section{Results and discussion}

Molecular modeling studies were performed by docking the synthetic model substrates of PET and PA 6,6 at the cutinase active site (Fig. 1). All mutations were done to create more space in order to fit the large inaccessible polymer in the active site of the cutinase. The modeling studies show that mutations L182A, L189A, L81A and V184A provide a better stabilization of the TI of the model substrates relatively to the native enzyme (Table 2), while the N84A mutation fails in stabilizing the TI model substrates due to the favorable interaction of the aspargine with the oxianion hole (Longhi and Cambillau, 1999). This is in accordance with the experimental activity obtained for $p$-NPB and PA 6,6 (Table 3). Higher stabilization is achieved with L182A as shown by the experimental results (Table 3 ). The modeling results suggest that L189A, L81A and V184A also stabilize both TI, but in a lower extent. Of

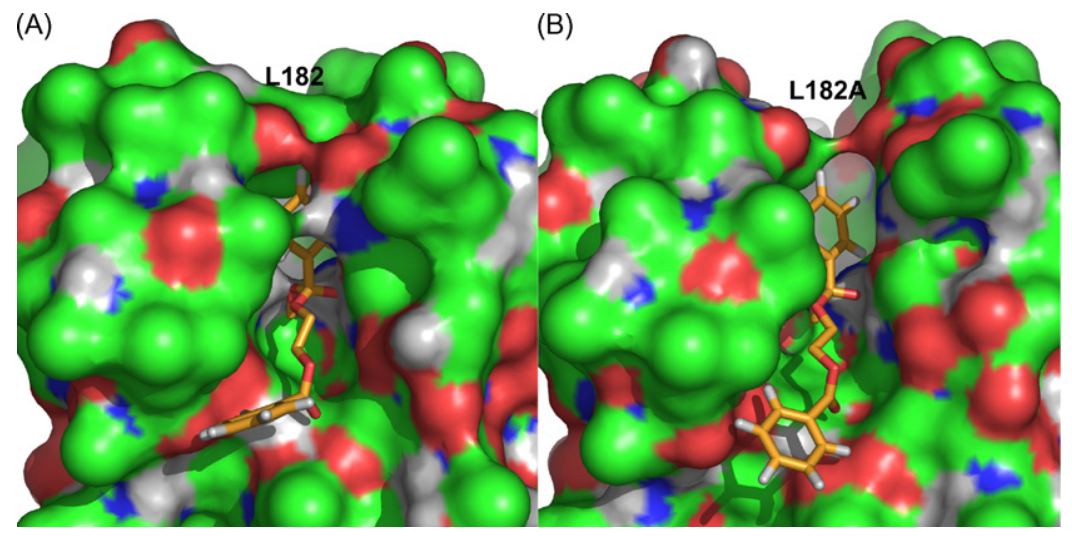

Fig. 2. Cutinase surface rendering of a representative configuration of an equilibrated simulation: native (A) and mutant cutinase L182A (B). L182A mutation is responsible for the highest increase of TI stabilization and enzymatic activity toward the 1,2-ethanodiol dibenzoate substrate. The 1,2-ethanodiol dibenzoate TI model is rendered in sticks. 
all these four mutations found to stabilize the TI theoretically, experimentally L182A, L81A and V184A displayed an increased activity for PET fibers, while L189A showed a decreased activity. Experimentally, in the case of PA 6,6 fibers, a higher hydrolytic activity was obtained with L182A form (119\%) while L189A, V184A and L81A displayed a slight decrease (Table 3). Structural analysis of the enzyme active site suggests that, replacing the bulky side chain of L182 by a smaller residue such as alanine (the L182A mutant) provides a less restrained active site, allowing a better accommodation of the model substrate, which gave the best enzyme activity improvement. This mutation allows the opening of the hydrophobic cleft of the enzyme active site, providing a better fit and stabilization of both model substrates than the native enzyme. The modeling studies also predict that the longer polymer chain in PET and PA 6,6 fabrics will also be more stabilized by this modified enzyme, which is corroborated by the experimental results, since there is a wider channel in the active site for these polymers to go through (Fig. 2).

The activity of cutinases towards PET and PA 6,6 fibers was expressed as mmolar (mM) of soluble terephthalic acid and soluble amines, respectively, obtained after a certain period of time. Due to the fact that these substrates are solid, no proper Michaelis-Menten kinetic could be calculated. Since we wanted to compare performances of each mutant enzyme based on equal amounts of protein, we expressed those estimated activities in $\mathrm{mM}$ of hydrolysis products.

The experimental hydrolytic activity on $p$-NPB was higher for all the mutant enzymes, when compared with the native cutinase, with the exception of N84A, which is explained by the modeling studies on basis of the favorable interaction of the aspargine with the oxianion hole (Table 3). Modified cutinases L182A and V184A have shown a remarkable increase in activity on $p$-NPB. Hydrolytic activity of L182A form increased more than four-fold. This seems to be a promising mutation to modify the hydrophobic surface of polyamide and polyester fibers. Concentrations of PET hydrolysis products were calculated after $24 \mathrm{~h}$ of PET fabric incubation with the enzyme, in the linear area of substrate conversion. Again L182A was the most active enzyme. The relative ratios of activities were similar for PET fibers and $p$-NPB, except for L189A and N84A.

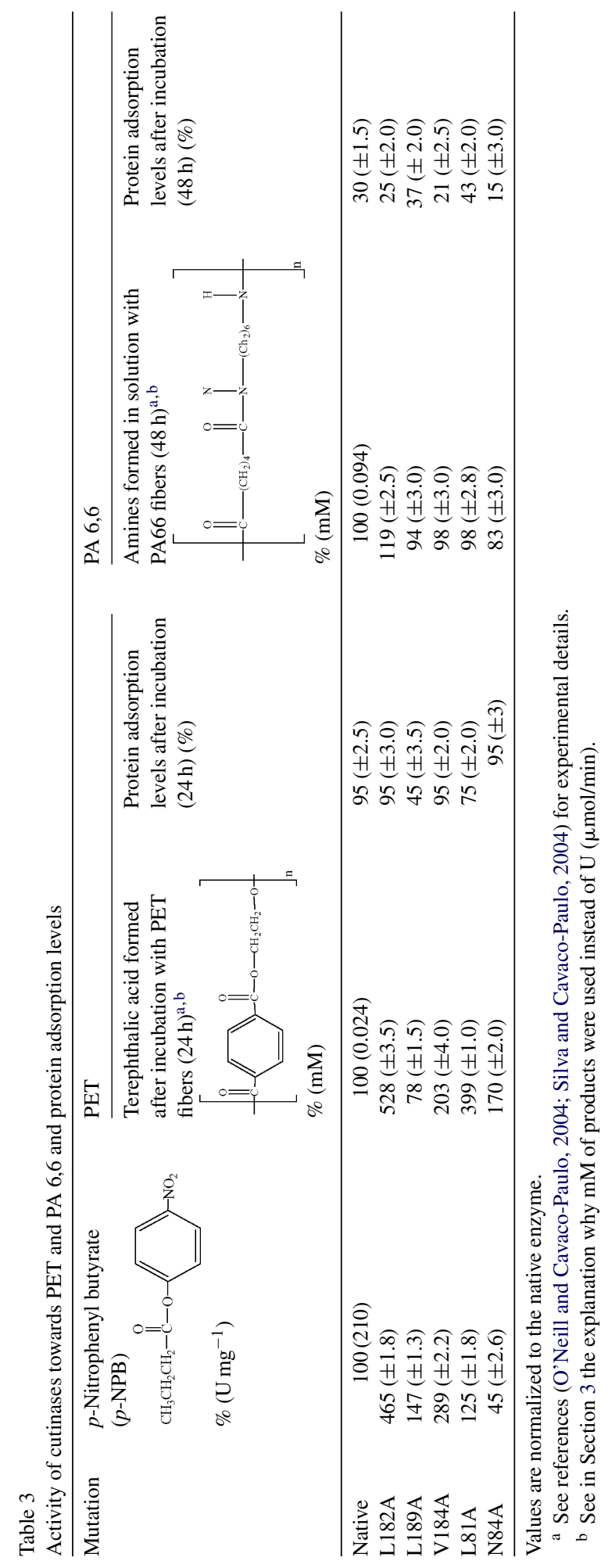


Cutinase is also able to biodegrade polyamide 6,6 substrates, but the designed mutations failed to give a clear increase of activity (Table 3). Just 19\% of increase was found for L182A. These results tend not to be in agreement with the modeling studies of the free energy of stabilization of TI for all mutant enzymes for polyamide 6,6 (Table 2).

Given that PET and PA 6,6 fibers are mostly hydrophobic, the adsorption properties of native and mutant unbound enzymes were modeled considering an analysis based on the total enzyme hydrophobic surface. Modified enzymes tested have an equal or lower percentage of hydrophobic surface in comparison with the native, as it was expected (Table 4), given that large hydrophobic residues were changed by smaller ones (with the exception of N84, which is polar). Our studies predict that L182A, N84A and L81A do not significantly affect the adsorption by the hydrophobic fibers, but V184A and L189A show a decrease in hydrophobic area, suggesting that fiber adsorption is reduced in this order. The modeling studies predictions are not in total agreement with the experimental results. N84A, L81A, V184A and L189A displayed different behavior of protein adsorption levels for both fibers when compared with the modeling studies. On the other hand, the L182A seems to maintain the same adsorption properties as the native enzyme for PET fibers and a slight decrease in the case of PA 6,6.

Given that the biotransformation of a fiber is a heterogeneous reaction, a pre-adsorption of the enzyme on the solid substrate is assumed before the catalysis can proceed. By looking at adsorption data it is possible to verify that cutinase adsorption levels are higher for PET than for PA 6,6 (Table 3). For the same concentrations of native cutinase, PET fibers

Table 4

Hydrophobic surface percentage (hydrophobic surface/total surface) with SE of native and mutated enzymes (Eisenhaber et al., 1995)

\begin{tabular}{lll}
\hline Enzyme & $\begin{array}{l}\text { Hydrophobic surface } \\
\text { (hydrophobic/total) }(\%)\end{array}$ & $\begin{array}{l}\text { Standard } \\
\text { error (SE) }\end{array}$ \\
\hline Native & 40.710 & 0.096 \\
L81A & 40.780 & 0.192 \\
N84A & 40.650 & 0.243 \\
L182A & 40.610 & 0.147 \\
V184A & 40.560 & 0.154 \\
L189A & 40.410 & 0.185 \\
\hline
\end{tabular}

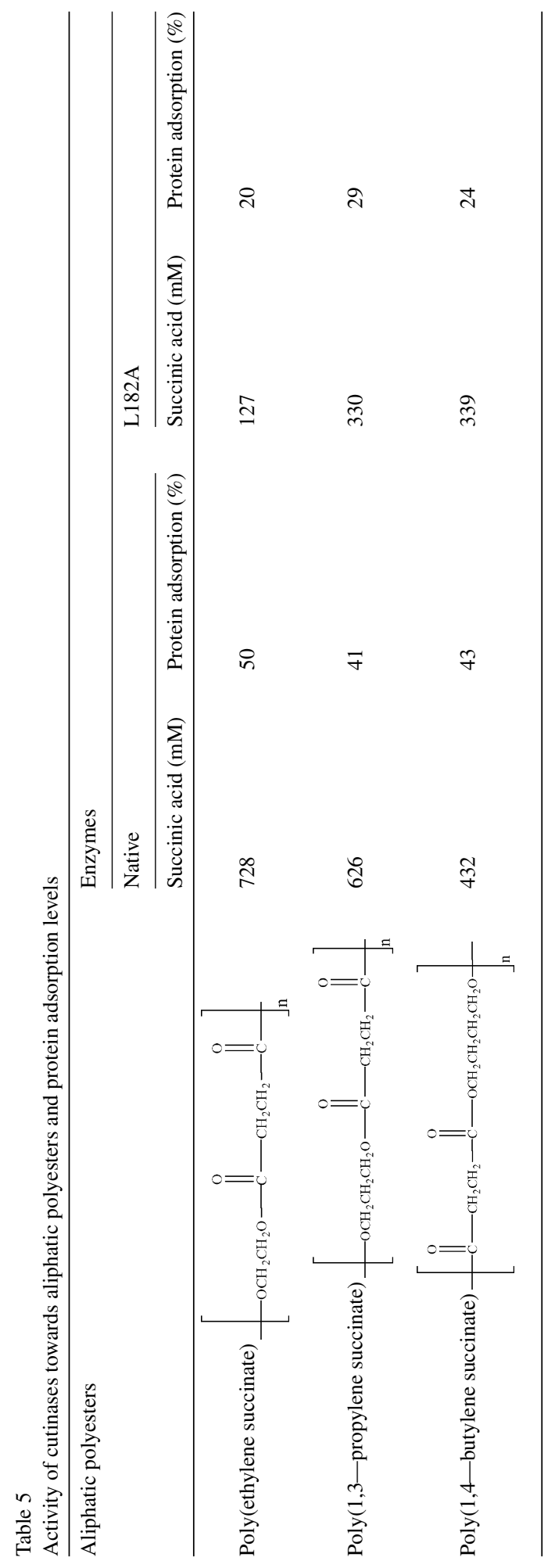


seems to be fully covered with enzyme $( \pm 95 \%)$ while this level was not reached for PA 6,6 fibers $( \pm 30 \%)$. Despite the stabilization of TI for several mutant cutinases, other adsorption and substrate recognition issues seem to play a major role on the enzymatic hydrolysis of solids substrates by cutinase. According to these results, L182A was considered to be the most promising enzyme for future studies.

We further measured the activity of the native and L182A cutinases towards aliphatic polyesters, which resemble the original cutin substrate. Apparently, the native form seems to have a decrease of activity and protein adsorption levels as the hydrophobicity of the substrate increases (Table 5). The opposite seems to happen with L182A, which presents a lower hydrophobic area (Table 4). However, the space created by the substitution of leucine by alanine close to the active site, appears to be enough to better "accommodate" hydrophobic aliphatic substrates. These results seem to indicate that cutinase is designed to recognize aliphatic chains, being one of the reasons why this enzyme shows activity towards the aliphatic structure of polyamide 6,6 .

In summary, we have obtained cutinases with enhanced activity towards polyester fibers, namely L81A and L182A. The increase in activity of these mutations can be explained by a higher stabilization of TI and a better accommodation of the substrate, as has been shown by our modeling studies. Furthermore, the L182A mutation does not affect the adsorption levels. Regarding polyamide treatment, our findings suggest that these fibers can be more efficiently modified when L182A cutinase is used. Being cutinase an esterase, it seems unlikely that it will biodegrade polyamide substrates. However, our findings suggest that the similarity of polyamide structure with cutin and the diversified substrate recognition of cutinase, might explain the ability of this enzyme to modify the surface of these fibers, showing however a slow enzymatic kinetics (Silva and Cavaco-Paulo, 2004).

\section{Acknowledgments}

This work was supported by the Biosyntex Project, no. G5RD-CT-2000-30110, from the European Community under the "Competitive and Sustainable Growth" Program and by the PhD grants: SFRH/BD/
22490/2005 and SFRH/BD/22149/2005, from Fundação para a Ciência e a Tecnologia (Portugal).

\section{References}

Ansaldi, M., Lepelletier, M., Mejean, V., 1996. Site-specific mutagenesis by using an accurate recombinant polymerase chain reaction method. Anal. Biochem. 234 (1), 110-111.

Barker, J.A., Watts, R.O., 1973. Monte-Carlo studies of dielectric properties of water-like models. Mol. Phys. 26, 789-792.

Berendsen, H.J.C., Postma, J.P.M., van Gunsteren, W.F., Dinola, A., Haak, J.R., 1984. Molecular-dynamics with coupling to an external bath. J. Chem. Phys. 81, 3684-3690.

Berendsen, H.J.C., van der Spoel, D., van Drunen, R., 1995. Gromacs-a message-passing paralell molecular-dynamics implementation. Compt. Phys. Commun. 91, 43-56.

Beveridge, D.L., Dicapua, F.M., 1989. Free-energy via molecular simulation-applications to chemical and biomolecular systems. Annu. Rev. Biophys. Chem. 18, 431-492.

Bradford, M.M., 1976. A rapid and sensitive method for the quantification of microgram quantities of protein utilizing the principle of protein-dye binding. Anal. Biochem. 72, 248-254.

Carvalho, C.M.L., Aires-Barros, M.R., Cabral, J.M.S., 1998. Cutinase structure, function and biocatalytic applications. Electron. J. Biotechnol. 1, 91-113.

Carvalho, C.M.L., Aires-Barros, M.R., Cabral, J.M.S., 1999. Cutinase: from molecular level to bioprocess development. Biotechnol. Bioeng. 66, 17-34.

Eisenhaber, F., Lijnzaad, P., Argos, P., Sander, C., Scharf, M., 1995. The double cubic lattice method-efficient approaches to numerical-integration of surface-area and volume and to dot surface contouring of molecular assemblies. J. Comp. Chem. 16, 273-284.

Griswold, K.E., Mahmood, N.A., Iverson, B.L., Georgiou, G., 2003. Effects of codon usage versus putative $5^{\prime}$-mRNA structure on the expression of Fusarium solani cutinase in the Escherichia coli cytoplasm. Protein expression and purification. Prot. Expr. Purif. 27, 134-142.

Hermans, J., Berendsen, H.J.C., van Gunsteren, W.F., Postma, J.P.M., 1984. A consistent empirical potential for water-protein interactions. Biopolymers 23, 1513-1518.

Inoue, H., Nojima, H., Okayama, H., 1990. High efficiency transformation of Escherichia coli with plasmids. Gene 96, 23-28.

Laemmli, U.K., 1970. Cleavage of structural proteins during the assembly of the head of bacteriophage T4. Nature 277, 680685.

Lindahl, E., Hess, B., van der Spoel, D., 2001. GROMACS 3.0: a package for molecular simulation and trajectory analysis. J. Mol. Model 7, 306-317.

Longhi, S., Cambillau, C., 1999. Structure-activity of cutinase, a small lipolytic enzyme. Biochem. Biophys. Acta 1441, 185-196.

Longhi, S., Czjzek, M., Lamizin, V., Nicolas, A., Cambillau, C., 1997. Atomic resolution (1.0A) crystal structure of Fusarium solani cutinase: stereochemical analysis. J. Mol. Biol. 268, 779-799. 
O’Neill, A., Cavaco-Paulo, A., 2004. Monitoring biotransformations in polyester fibres. Biocatal. Biotransform. 22 (5/6), 353-356.

Sambroock, J., Fritsch, E.F., Maniatis, T., 1989. Molecular Cloning: A Laboratory Manual, second ed. Cold Spring Harbor Laboratory, New York.

Sanger, F., Nicklen, S., Coulson, A.R., 1977. DNA sequencing with chain-terminating inhibitors. Proc. Natl. Acad. Sci. U.S.A. 74, 5463-5467.

Scott, W.R.P., Hunenberger, P.H., Tironi, I.G., Mark, A.E., Billeter, S.R., Fennen, J., Torda, A.E., Huber, T., Kruger, P., van Gunsteren, W.F., 1999. The GROMOS biomolecular simulation program package. J. Phys. Chem. A 103, 3596-3607.

Shirai, K., Jackson, R.L., 1982. Lipoprotein lipase-catalyzed hydrolysis of $p$-nitrophenyl butyrate. Interfacial activation by phospholipid vesicles. J. Biol. Chem. 257, 1253-1258.

Silva, C., Cavaco-Paulo, A., 2004. Monitoring biotransformations in polyamide fibres. Biocatal. Biotransform. 22 (5/6), 357-360.
Silva, C., Carneiro, F., O’Neill, A., Fonseca, L.P., Cabral, J.M.S., Guebitz, G., Cavaco-Paulo, A., 2005. Cutinase-a new tool for biomodification of synthetic fibres. J. Polym. Sci., Part A: Polym. Chem. 43, 2448-2450.

Smith, P.E., van Gunsteren, W.F., 1994. Consistent dielectricproperties of the simple point-charge and extended simple point-charge water models at 277 and $300 \mathrm{~K}$. J. Chem. Phys. 100, 3169-3174.

Tironi, I.G., Sperb, R., Smith, P.E., van Gunsteren, W.F., 1995. A generalized reaction field method for molecular-dynamics simulations. J. Chem. Phys. 102, 5451-5459.

van Gunsteren, W.F., Berendsen, H.J.C., 1990. Computer simulation of molecular dynamics: methodology, applications and perspectives in chemistry. Angew. Chem. Int. Ed. 29, 992-1023.

Warshel, A., Naray-Szabo, G., Sussman, F., Hwang, J.K., 1989. How do serine proteases really work. Biochemistry 28, 36293637. 